\title{
Sentimentalismo escocés: Hume y Smith contra el egoísmo moral
}

\author{
MARÍA ALEJANDRA CARRASCO* \\ Pontificia Universidad Católica de Chile (Chile) \\ mcarrasr@uc.cl
}

\begin{abstract}
Resumen
Los filósofos sentimentalistas escoceses David Hume y Adam Smith proponen dos estrategias distintas para restringir las tendencias egoístas de la naturaleza humana. A pesar de las evidentes similitudes de sus propuestas morales, Smith encuentra dentro del ser humano la capacidad para transformar sus pasiones parciales y aspirar hacia ideales de perfección. El sentimentalismo de Hume, en cambio, no permite la autotransformación de la persona, y debe apoyarse en convenciones sociales para manipular y redirigir los impulsos egoístas desde fuera. Ambos logran su objetivo. Pero mientras Hume se conforma con una moral funcional para la vida social, Smith abre una nueva dimensión de desarrollo para el ser humano.
\end{abstract}

Palabras clave: David Hume, Adam Smith, sentimentalismo moral, convenciones, autocontrol/autodirección.

\section{Scottish Sentimentalism: Hume and Smith against moral egoism}

\begin{abstract}
The Scottish sentimentalist philosophers David Hume and Adam Smith suggest different strategies for restricting and accommodating human selfish tendencies. In spite of the obvious similarities of their moral proposals, Smith finds within the human being the capacity to transform his partial passions and to aspire to ideals of perfection. In contrast, Hume's sentimentalism does not allow for self-transformation, and must rely on social conventions to manipulate and redirect selfish impulses from without. Both attempts achieve their goal. However, while for Hume peaceful social interaction seems to be the only aim of morality; for Smith morality also opens a new dimension of development for the human being.
\end{abstract}

Key words: David Hume, Adam Smith, sentimentalism, conventions, self-command.

\footnotetext{
* $\quad$ Doctora en Filosofía, es profesora asociada del Instituto de Filosofía de la Pontificia Universidad Católica de Chile. Entre sus publicaciones destacan múltiples artículos sobre los filósofos de la Ilustración Escocesa, tales como "Adam Smith: Reconstruction of Practical Reason" (2004); "De Hutcheson a Smith: Un sentimentalismo 'sofisticado" (2009) y "Hutcheson, Smith and Utilitarianism" (2011).

Agradezco al Proyecto Fondecyt 1170260, Conicyt, Chile.
} 
INTRODUCCIÓN

David Hume y Adam Smith, dos de los principales filósofos sentimentalistas de la Ilustración Escocesa, elaboraron sus respectivas éticas en respuesta a las teorías egoístas de Hobbes y Mandeville. Aunque los pensadores escoceses reconocían que el amor a sí mismo ${ }^{1}$ era un principio importante en la naturaleza humana, rechazaban la idea de que fuera la única motivación posible para nuestras acciones. Hume, por ejemplo, dice que cuando aprobamos las cualidades que son ventajosas para quien las posee, "no puede ser el amor a sí mismo lo que convierte su contemplación en agradable para nosotros, los espectadores, y lo que promueve nuestra estima y aprobación. ... [T] odo recelo a causa de consideraciones egoístas está aquí totalmente excluido. Es un principio absolutamente diferente el que impulsa nuestro corazón y nos interesa en la felicidad de la persona a la que contemplamos" (Hume, 1998: 6.32). Smith, haciendo eco de su predecesor, comienza The Theory of Moral Sentiments (TMS) observando que: "Por más egoísta que se pueda suponer al hombre, existen evidentemente en su naturaleza algunos principios que le hacen interesarse por la suerte de los otros, y hacen que la felicidad de estos le resulte necesaria, aunque no derive de ella más que el placer de contemplarla" (Smith, 1982: I.i.1.13).

Esta visión no reduccionista de la motivación humana supone para ambos autores enfrentan un mismo desafío, a saber, explicar cómo se coordinan los motivos benevolentes y los egoístas en la acción del hombre virtuoso (Hanley, 2015: 720). Smith insiste a lo largo de su TMS en que "[a]unque sea verdad que cada individuo, en su corazón, se prefiere naturalmente a toda la humanidad, [deberá] moderar la arrogancia de su amor propio y atenuarlo hasta el punto en que las otras personas puedan acompañarlo" (Smith, 1982: II.ii.2.1). Y Hume, en su Treatise of Human Nature, reconoce también que "[t]odos nosotros tenemos una extraordinaria parcialidad por nosotros mismos, de manera que, si en cada momento dejáramos escapar libremente nuestros sentimientos en este particular, estaríamos siempre fuertemente indignados unos con otros" (Hume, 2007: 3.3.2.10). De aquí que ambos asuman la tarea de descubrir los medios con los que la moral restringe la autopreferencia o parcialidad innata, que es la principal fuente de conflicto en la vida social.

1 En este artículo usaré indistintamente los términos amor a sí mismo, amor propio, interés propio y autopreferencia.

2 Las dos obras más importantes de Hume para su teoría moral son la An Enquiry concerning the Principles of Morals, que aquí se citará con el año seguido del número de la sección y luego del parágrafo dentro de la sección; y A Treatise of Human Nature, que se citará con el año seguido del número del libro, parte, sección y parágrafo.

3 El texto se citará con el año seguido de la parte, sección, capítulo y parágrafo. 
En este artículo exploraré los distintos medios que estos autores identifican como estrategias naturales para este fin, y cómo estos mismos medios revelan diferencias sustantivas entre sus respectivos sentimentalismos. Hume recurre a las convenciones, acuerdos sociales tácitos de respetar ciertas reglas que crean prácticas mutuamente ventajosas ${ }^{4}$. Smith, en cambio, recurre a la simpatía mutua o a esa tendencia innata que las personas tenemos a aprobar y sentirnos aprobados por los demás. Como "[n]ada nos agrada tanto como comprobar que otras personas sienten las mismas emociones que laten en nuestro corazón — dice Smith-, y nada nos disgusta tanto como la apariencia de lo contrario" (Smith, 1982: I.i.2.1), nos esforzamos por modular nuestros sentimientos hasta un punto en que puedan ser aprobados por los demás. Mi tesis será que estos distintos dispositivos para controlar la autopreferencia manifiestan la diversa comprensión que estos autores tienen respecto de la naturaleza y función de la moral, dependiente en parte de la maleabilidad que atribuyen a las pasiones. Hume tiene una visión más bien mecánica de la constitución afectiva humana, y asigna a la moral la función de redirigir y coordinar los movimientos automáticos de las pasiones para posibilitar una vida común armoniosa. Para Hume la superación del egoísmo y del conflicto social es el fin de la moral. En contraste, Adam Smith piensa que la moral es capaz de transformar nuestras pasiones desde dentro. La moral abre una nueva dimensión en la vida humana y su función, más allá de la paz y armonía social, es promover la perfección de la persona.

\section{David Hume}

\subsection{Círculos de cercanía y tipos de motivación}

Tanto Hume como Smith piensan que el mérito moral procede de los motivos de la persona, de que sus motivos sean virtuosos ${ }^{5}$. Hume afirma que cuando nos relacionamos con personas cercanas actuamos naturalmente por motivos benevolentes, y que si estos fueran los únicos motivos en nuestro corazón no habría conflicto en el mundo: "Es fácil darse cuenta de que un afecto cordial hace que entre amigos todo sea común" (Hume,

\footnotetext{
4 Hume describe las convenciones como "una idea de interés común, que es la percepción que cada hombre siente en su propio corazón, que la observa en sus semejantes y que la lleva, junto con otros, a un plan general o sistema de acciones que tiende a la utilidad pública" (Hume, 1998: 3.7).

5 "[T] odas las acciones virtuosas deben su mérito a motivos virtuosos y son consideradas como simples signos de estos motivos" (Hume, 2007: 3.2.1.4). En Smith: “...el sentimiento o afecto del corazón, del que depende toda acción y del que depende toda virtud o vicio...” (Smith, 1982: II.i.introd.2).
} 
2007: 3.2.2.17), dice Hume, y "Elevad hasta un grado suficiente la benevolencia de los hombres ... y haréis que la justicia se convierta en algo inútil, supliendo su lugar mediante virtudes mucho más nobles y bienes más valiosos" (Hume, 2007: 3.2.2.16; ver también Hume, 1998: 3.6). Sin embargo, esta no es la situación en que se encuentra la naturaleza humana. Cuando las sociedades empiezan a crecer la gente se ve forzada a ampliar sus círculos de interacción y debe relacionarse también con otras personas, a quienes no conocen y por quienes no sienten ningún afecto. En este tipo de interacción, dice Hume, el motivo que predomina es el del interés propio $^{6}$.

Este se convierte en el principal obstáculo para la existencia de la sociedad, debido a que cuando "se permite que el [amor propio] actúe a su libre arbitrio, en vez de comprometernos en acciones honestas resulta ser la fuente de toda injusticia y violencia" (Hume, 2007: 3.2.1.10). Hume no cree que exista un remedio natural para controlar estas pasiones parciales (Hume, 2007: 3.2.2.8); no hay motivos naturales para contrarrestar el amor a sí mismo. La solución, en cambio, proviene del artificio. "[O] bien, hablando con más propiedad - dice Hume- la naturaleza proporciona un remedio en el juicio y el entendimiento para lo que resulta irregular e inconveniente en las afecciones" (Hume, 2007: 3.2.2.9), ya que, aunque naturalmente seamos parciales con los nuestros, "somos capaces de ver las ventajas de una conducta más equitativa" (Hume, 1998: 3.13). De este modo, esa "extraordinaria parcialidad por nosotros mismos" (Hume, 2007: 3.3.2.10) nos lleva a establecer las que Hume llama "leyes de justicia" y "reglas de cortesía". Las primeras aseguran la propiedad y evitan los conflictos por el choque de intereses egoístas; las segundas evitan los conflictos por orgullo y vuelven grata la interacción social (Hume, 2007: 3.3.2.10). Cuando estas convenciones se consolidan, la sociedad florece.

Hume explica en detalle la génesis de las leyes de justicia, paradigma de las convenciones que se establecen para restringir el amor propio. Dice

\footnotetext{
6 Hume señala que "[e]n general, puede afirmarse que en la mente de los hombres no existe una pasión tal como el amor a la humanidad, considerada simplemente como tal y con independencia de las cualidades de las personas, de los favores que nos hagan o de la relación que tengan con nosotros" (Hume, 2007: 3.2.1.12). Los motivos benevolentes sí nos mueven cuando nos relacionamos con los más cercanos. Pero, “aunque en honor de la naturaleza humana haya que reconocer esta generosidad, es posible observar al mismo tiempo que una afección como esta, tan noble, en lugar de hacer a los hombres aptos para formar grandes comunidades es casi tan contraria a ello como el más mezquino egoísmo. Pues igual que cada uno se ama a sí mismo más que a cualquier otra persona, en este amor por los demás se guarda el mayor afecto para con los parientes y conocidos, de modo que esto ha de producir necesariamente una oposición de pasiones y una consecuente oposición de acciones, lo que no puede resultar sino peligroso para la recién establecida unión" (Hume, 2007: 3.2.2.6).
} 
que el mayor obstáculo para la constitución de la sociedad procede, por una parte, de nuestro egoísmo y generosidad limitados, y, por la otra, de la escasez e inestabilidad de los bienes externos (Hume, 2007: 3.2.2.7). Esta última circunstancia es particularmente relevante porque, de todas las pasiones, solo el ansia "por adquirir bienes y posesiones para nosotros y nuestros amigos más cercanos resulta insaciable, perpetua, universal y directamente destructora de la sociedad" (Hume, 2007: 3.2.2.12). Por ello, cuando la comunidad crece y empezamos a relacionarnos con quienes no tenemos lazos de afecto, se hace indispensable establecer una convención que asegure la estabilidad de los bienes. Esta se origina de manera natural. Cuando las personas comprenden que los principales conflictos sociales surgen de la fácil transición o inestabilidad de los bienes externos, buscan algún modo de fijar la propiedad. Y "esto no puede hacerse de otra manera que mediante una convención en la que participan todos los miembros de la sociedad, que confiere estabilidad a la posesión de estos bienes externos, dejando que cada uno disfrute pacíficamente de aquello que pudo conseguir gracias a su laboriosidad o su suerte" (Hume, 2007: 3.2.2.9). Esta convención no se opone a nuestras pasiones. $\mathrm{Al}$ contrario, aunque de un modo oblicuo, las sacia completamente. "[E]s evidente que la pasión se satisface mucho mejor restringiéndola que dejándola en libertad; como también es evidente que, preservando la sociedad, nos es posible realizar progresos mucho mayores en la adquisición de bienes que reduciéndonos a la condición de soledad y abandono individuales, consecuencias de la violencia y el libertinaje general" (Hume, 2007: 3.2.2.13).

Por consiguiente, en el sentimentalismo bumeano el interés propio es el motivo original para respetar las leyes de la justicia. Respetamos la propiedad ajena en la medida en que los otros también respeten la nuestra, y por este acuerdo tácito todos satisfacemos nuestros intereses? ${ }^{7}$. Este acuerdo basta mientras la comunidad es pequeña y el daño que provoca cada acto de injusticia es manifiesto. Sin embargo, cuando la comunidad crece, el daño ya no es evidente. En ese instante otro motivo debe concurrir en apoyo de la convención. Es decir, cuando el interés propio ("mi interés en que no se destruya la sociedad") deja de ser suficiente motivo

Ver, en nota 4 más arriba, la descripción bumeana de una convención. Respecto de la justicia, Hume hace ver que los beneficios de la justicia no siempre se siguen de cada acto particular de justicia, pero sí de todo el sistema de acciones. Todos los miembros de la sociedad se percatan de este interés. "[A] pesar de que los actos singulares de justicia puedan ser contrarios al interés público o privado, es cierto que el plan o esquema, considerado en conjunto, resulta altamente favorable; ... Cada miembro de la sociedad advierte este interés: cada uno lo comunica a los que le rodean, junto con la resolución que ha tomado de regular sus acciones por él, a condición de que los demás hagan lo propio" (Hume, 2007: 3.2.2.22). 
para no cometer injusticias - porque no se ve claro cómo una única injusticia pueda poner en riesgo toda la vida social - otro motivo debe venir a apoyar. En concreto, siempre percibimos el daño que sufrimos cuando somos víctimas directas de alguna injusticia, así como el daño que las injusticias provocan en otros. La injusticia, incluso cuando no afecta directamente nuestros intereses, nos desagrada; produce malestar en las víctimas y, por medio de la simpatía —o ese mecanismo psicológico por el que las personas comparten automáticamente los sentimientos que observan en otros ${ }^{8}$ - participamos de su malestar. La simpatía con el interés público será, entonces, la fuente de la aprobación moral de la justicia (Hume, 2007: 3.2.2.24).

Esta descripción genética de la justicia muestra que la obligación moral, o el sentirse moralmente obligado a cumplir con la justicia, es un motivo que viene a apoyar a la convención cuando el motivo natural para respetarla pierde fuerza debido a que las malas consecuencias de su violación dejan de ser evidentes. Podemos entonces concluir que en la teoría de Hume obedecemos las convenciones (restringimos la autopreferencia) básicamente por razones pragmáticas: por alguna utilidad percibida o por temor al castigo'. Este es el motivo original para constituirlas, y a este motivo

8 Según lo describe en Hume, 2007: 2.1.11, el mecanismo de la simpatía operaría de la siguiente manera: Observamos la conducta de otra persona e inferimos de ella sus causas (los sentimientos que la llevan a actuar asî́. Nos formamos así una idea de la pasión que la está moviendo. Esta idea se convierte luego en una impresión (es decir, en una pasión o sentimiento) por su relación con la impresión que tenemos continuamente de nosotros mismos, de nuestro 'yo'. En otras palabras, como siempre tenemos presente, de modo muy vivo, nuestro propio yo; y como todas las personas nos relacionamos por semejanza, los sentimientos de otra persona también tienen alguna relación conmigo. Así, cuando pienso en la idea de alguna pasión de otro, la vivacidad de la impresión de mi yo aviva esa idea y la convierte en impresión, es decir, en la pasión misma. De este modo, yo empieza a sentir la misma pasión que la persona que observo. Para un análisis de la simpatía en Hume, y especialmente la continuidad de su noción de simpatía entre el Treatise y Enquiry (Debes, 2007).

9 Aunque este último motivo está solo implícito en la descripción genética de la justicia, sí es mencionado en relación a otras dos convenciones. Respecto de la obligación de cumplir las promesas, Hume dice: "Cuando alguien dice que promete una cosa, expresa de hecho la resolución de cumplirla y, a la vez, mediante el empleo de esa fórmula verbal, se somete al castigo de que nunca más se confíe en él en caso de incumplimiento" (Hume, 2007: 3.2.5.10). Luego, respecto de la virtud artificial de la castidad, también admite que para contrarrestar la fuerte tentación a la infidelidad, "No parece que sea posible otra restricción sino la de castigar [a las mujeres] por medio de la mala fama o reputación" (Hume, 2007: 3.2.12.4). En relación con la justicia, el temor al castigo se podría inferir del caso de las creaturas racionales inferiores (Hume, 1998: 3.18). Las leyes de justicia, para Hume, son leyes de estabilidad de las posesiones, y requieren reciprocidad. En este sentido es fácil entender que solo se aplican a seres capaces de propiedad y de ser obliga- 
se une luego el sentimiento moral. Sin embargo, el sentimiento que apoya al motivo original nunca lo reemplaza del todo. Aunque cumplamos los deberes por razones morales, si el motivo pragmático no estuviera al menos latente, el motivo moral desaparecería. Esa es la situación que describe Hume al decir que cuando las circunstancias externas cambian radicalmente o cuando por alguna razón las leyes de justicia dejan de ser útiles, estas se suspenden (Hume, 1998: 5, 6-9). Si el motivo interesado (pragmático) para restringir el autointerés desaparece (si deja de ser útil restringirlo), el motivo moral que lo apoya también desaparece.

\subsection{El automatismo de las pasiones}

En la teoría moral de Hume se juzgan como virtuosas aquellas cualidades del carácter que promueven la felicidad del agente o la de aquellos afectados por su acción (Hume, 1998: 9.1). Compartimos su placer por simpatía, que se constituye de este modo en la principal fuente de las distinciones morales (Hume, 2007: 3.3.6.1) ${ }^{10}$. Pero, aunque la simpatía influya en el gusto y en los sentimientos de aprobación o reprobación ${ }^{11}$, dirá Hume, "es muy débil como para controlar nuestras pasiones" (Hume, 2007: 3.2.2.24). Este punto es insistentemente recalcado por el autor: "Si se quiere que dirijan nuestras pasiones, los sentimientos tienen que llegar al corazón; pero para ejercer influencia sobre nuestro gusto no necesitan ir más allá de la imaginación" (Hume, 2007: 3.3.1.23). La aprobación simpatética afecta nuestros juicios, pero no tiene el poder para transformar nuestros sentimientos.

Por otro lado, como la simpatía varía según la distancia de las personas con quienes simpatizamos, y como la aprobación moral no puede depender de la vivacidad contingente de nuestros sentimientos, Hume dice que para realizar juicios morales debemos elegir un punto de vista común desde el que contemplar el objeto juzgado y corregir, en la reflexión, las diferencias de simpatía. La aprobación moral, en última instancia, se identifica con el placer que sentimos al asumir esa perspectiva, que resulta de

dos por esas leyes. Los seres inferiores del ejemplo, aunque racionales, pueden ser incapaces de regular su conducta por estas reglas. Pero esta no es la razón que da Hume para no restringir nuestra avidez en relación con estas criaturas. Lo que dice es que ellas son "incapaces de toda resistencia" y de "hacernos sentir los efectos de su resentimiento". Es decir, son incapaces de retaliación, de castigar a sus agresores. Esto podría interpretarse diciendo que, junto a la mejor satisfacción de nuestra avidez, el miedo a la reacción de la víctima también es un motivo natural para restringir nuestro amor propio.

10 La simpatía en Hume se rige principalmente por dos de los principios de asociación que explica en su teoría de la imaginación, a saber, la contigüidad y la semejanza.

11 En el sentimentalismo, el juicio moral es un sentimiento. Ver Sayre-McCord (2014). 
la consideración en general - sin referencia al interés particular- del placer que el carácter de una persona provoca a sí misma o a otras. Al explicar esta perspectiva, Hume afirma que: "La experiencia nos enseña bien pronto cómo corregir nuestros sentimientos, o por lo menos, nuestro lenguaje ahí donde los sentimientos son tenaces e inalterables" (Hume, 2007: 3.3.1.16. Énfasis mío). También dice: "No siempre las pasiones siguen nuestras correcciones, pero estas sirven suficientemente para regular nuestras nociones abstractas; y son esas correcciones las únicas tenidas en cuenta en nuestras apreciaciones generales de los grados de virtud y vicio" (Hume, 2007: 3.3.1.21. Énfasis mío), y “aunque no siempre intervenga el corazón en estas nociones generales, ni regule sus sentimientos de amor u odio por ellas, son, con todo, suficientes para permitirnos hablar con sentido, y sirven a todos nuestros propósitos en la vida común, sea en el púlpito, en el teatro o en las escuelas" (Hume, 2007: 3.3.3.2). En suma, Hume está señalando que ni la simpatía espontánea ni la simpatía corregida tienen el poder de transformar nuestros sentimientos.

No obstante, aunque la simpatía no pueda cambiar nuestras pasiones, las convenciones sí pueden manipularlas desde fuera y cambiar su dirección. Las convenciones se aprovechan de los principios o mecanismos naturales que automáticamente regulan nuestras pasiones, entre los que destaca el principio que dice que "todo lo que es contiguo en el espacio o en el tiempo... actúa comúnmente con más fuerza que un objeto a mayor distancia o más obscurecido" (Hume, 2007: 3.2.7.2) ${ }^{12}$. La justicia, o aquella convención que restringe el amor propio para una mejor satisfacción del mismo amor propio, es un muy buen ejemplo. La justicia no afecta al motivo del amor propio; solo cambia la dirección de la pasión mostrándonos otro objeto (la preservación de la sociedad) que lo satisface mejor. Este es un dispositivo de gran eficacia cuando ese "otro objeto" (la preservación de la sociedad) está efectivamente a la vista. Pero cuando la sociedad crece y la posición relativa de los objetos cambia, la ventaja actual de una injusticia se percibe como mucho más cercana que el eventual daño que una única injusticia pudiera ocasionar a la sociedad. En este caso, "[a]unque estemos plenamente convencidos de que este segundo objeto supera [en valor] al primero, somos incapaces de regular nuestras acciones por este juicio, sino que nos plegamos a lo que solicitan nuestras pasiones, que abogan siempre

$12 \mathrm{Al}$ explicar las virtudes naturales, Hume también destaca que la imaginación se ve más afectada por lo particular que por lo general (Hume, 2007: 3.3.1.13). El mecanismo por el que se mueven las pasiones lo desarrolla extensamente en el segundo libro del Treatise. 
en favor de lo que esté cercano o contiguo" (Hume, 2007: 3.2.7.2. Énfasis mío) $)^{13}$.

Si estamos determinados a seguir la dirección de las pasiones, ¿qué hacer cuando la justicia, esencial para la existencia de la sociedad, está en peligro? La respuesta es una nueva convención que re-sitúa los objetos de nuestras pasiones. El remedio a esta debilidad natural —o a la propensión a preferir lo cercano a lo remoto- es, nuevamente, "cambiar nuestras circunstancias y situación, haciendo de la observancia de las leyes de la justicia nuestro interés más cercano, y de su violación, el más remoto" (Hume, 2007: 3.2.7.6) ${ }^{14}$. Cambiamos las circunstancias externas porque "es imposible cambiar o corregir ninguna cosa importante en nuestra naturaleza". El estudio, la reflexión, el consejo, la meditación y la resolución son medios inefectivos, porque "[l]os hombres son incapaces de curar radicalmente, lo mismo en ellos que en los demás, esa mezquindad de alma que les lleva a preferir lo presente a lo remoto" (Hume, 2007: 3.2.7.6). No pueden cambiar su naturaleza, pero sí pueden cambiar su situación.

Hume funda su teoría moral sobre esta visión mecanicista de las pasiones. Las pasiones reaccionan y tienden a sus objetos con intensidad proporcional a su distancia y brillo. No tenemos la capacidad de transformarlas, pero sí podemos redirigirlas alterando la posición de los objetos hacia los que ellas automática y necesariamente tienden. Podemos manipular las pasiones desde fuera, cambiando las circunstancias. Esa es la función que cumplen las convenciones, esas instituciones sociales creadas como dispositivos pragmáticos para canalizar las pasiones antisociales. Las convenciones se sirven del automatismo y fuerza de las pasiones para coordinar los impulsos interesados de todos los miembros de la sociedad en un sistema cooperativo que satisfaga, aunque de modo oblicuo, esos impulsos. Básicamente las convenciones regulan nuestras pasiones cambiando las circunstancias, poniendo algunos objetos de interés más cerca o anexando premios y castigos a determinadas conductas.

En consecuencia, para mostrar cómo se coordinan los motivos egoístas y los benevolentes en la conducta de una persona virtuosa, Hume comienza por separar áreas. En una, donde nos relacionamos con quienes amamos y nos mueven principios benevolentes, no es necesario introducir ningún tipo de corrección por parte de la moral. En la otra, donde nos relacionamos con quienes nos son indiferentes y nos mueve el amor propio, necesitamos convenciones que refrenen los impulsos inmediatos y

13 Cohon (2008), explica que cuando la sociedad crece las violaciones particulares a las reglas de justicia difícilmente ponen en riesgo la sociedad. Así, al comparar, la ventaja que se pueda obtener de un acto de injusticia es superior a ese peligro.

14 Esta nueva convención es la del gobierno civil, ver Hume, 2007: 3.2.7. 
nos induzcan a conformarnos a un esquema de interacción que, en última instancia, también satisface el amor propio. Las convenciones redirigen las pasiones sin cambiarlas. Nuestros motivos son los mismos - por decirlo así- "antes y después de la moral". El amor propio no es realmente "superado" en esta ética; pero sí es canalizado en lo que Hume llama las "relaciones interesadas entre los hombres" (Hume, 2007: 3.2.5.10) ${ }^{15}$, relaciones que nos benefician a todos.

En síntesis, la moral es necesaria para la interacción social armoniosa. Necesitamos un lenguaje común, y la moral lo proporciona. Necesitamos restringir nuestro amor propio en las acciones externas, y la moral proporciona los medios para hacerlo a través de las convenciones. Y, para Hume, esto es todo lo que se requiere para hacer del hombre un miembro apto para la vida social (Hume, 2007: 3.2.2.13.).

\section{ADAM SMITH}

Tal como el de su antecesor, el sentimentalismo moral de Adam Smith también se estructura en torno a los medios con los que se restringe el amor propio o las motivaciones egoístas. Sin embargo, como se aprecia desde los primeros capítulos de la TMS y su propio concepto de simpatía, su solución es muy distinta a la de Hume. Para Smith, el mismo proceso simpatético corrige la tendencia que tenemos a sobrevalorar los propios sentimientos. De este modo, en contraste con Hume, Smith encuentra el medio para restringir la autopreferencia en una característica innata de nuestra psicología, y no en un artificio o una convención externa. Esta disimilitud configurará una psicología moral muy diversa que, a su vez, dará lugar a una ética de virtudes muy distinta.

La diferencia entre estas dos nociones de simpatía queda bien resumida en la distinción que hace Samuel Fleischacker entre simpatía-contagio y simpatía-proyección (Fleischacker, 2012: 276). La primera obedece a los movimientos mecánicos de las pasiones; el espectador es pasivo mientras los sentimientos pasan causalmente de una persona a otra (Fleischacker, 2017: 7. También Fleischacker, 2012: 276, y Hanley, 2015: 711). En contraste con esa noción, en la simpatía-proyección el espectador debe ser

15 Este ámbito de interacción o intercambio interesado es totalmente independiente de la interacción desinteresada, natural con los cercanos. De hecho, cuando el comercio interesado "comienza a realizarse y a predominar en la sociedad, no supone la abolición completa de aquel otro intercambio amistoso y de buenos oficios, más generoso y noble. Puedo seguir favoreciendo a las personas por quienes siento afecto y a quienes trato con mayor asiduidad sin la menor perspectiva de obtener un provecho por ello, y estas personas pueden corresponder de la misma manera, sin más intención que la de recompensar mis pasados favores" (Hume, 2007: 3.2.5.10). 
activo, pues necesita salir de sí mismo para identificarse imaginativamente con el agente. El espectador debe ponerse en la situación del otro, ponerse en sus zapatos o cambiar imaginariamente de posiciones para devenir, como dice Smith, "en alguna medida, la misma persona con él" (Smith, 1982: I.i.1.2-3).

Este nuevo modo de comprender la simpatía tiene consecuencias decisivas para la ética. En primer lugar, cambia el punto de vista desde el que se realizan los juicios morales. Con la simpatía bumeana estos se hacen desde una perspectiva externa, donde el espectador simplemente replica los sentimientos del agente y de aquellos afectados por su acción. El espectador recibe esos sentimientos como en una transfusión ${ }^{16}$. Con la simpatía-proyección, en cambio, el espectador debe asumir la perspectiva interna del agente y crear en sí mismo, desde abajo, los sentimientos que imagina que el agente tiene (Fleischacker, 2012: 292). Una segunda consecuencia que deriva del cambio de perspectiva es que la simpatía ya no surge de la visión de las pasiones del agente sino, como dice Smith, "de la situación que la provoca" (Smith, 1982: I.i.1.10). Naturalmente, al asumir la perspectiva del otro ya no tenemos al frente sus sentimientos sino al objeto o la situación a la que estos responden (Darwall, 1999: 144).

Finalmente, una tercera consecuencia de esta simpatía es que al proyectarnos en la posición del otro se abre la posibilidad de que los sentimientos que en su nombre tenemos no coincidan con los que el otro efectivamente tiene. Así, la simpatía-proyección "nos pone en la situación de secundar o de disentir de los sentimientos del otro. Como dice Smith, podemos expresar nuestro parecer sobre la 'propiedad' de [i.e. cuán apropiados son] sus sentimientos" (Darwall, 1998: 268). Si observamos que hay correspondencia entre los sentimientos del agente y los nuestros, los aprobamos, los juzgamos apropiados, justificados, adecuados para la situación que los provoca. Si no hay correspondencia, no hay simpatía y juzgamos que los sentimientos del agente son inapropiados. "Aprobar las pasiones de otro - dice Smith- es lo mismo que observar que podemos simpatizar completamente con ellas" (Smith, 1982: I.i.3.1). Por tanto, la aprobación moral en Smith también se identifica con un sentimiento de placer ${ }^{17}$, pero a diferencia de Hume es un sentimiento que indica adecuación, proporción

\footnotetext{
16 Smith también da cuenta de esta simpatía en TMS (1982: I.i.1.6), aunque dice que ella es muy imperfecta. La noción de simpatía de Smith no será tampoco una mera complejización de esta misma, sino que involucrará otras facultades y, sobre todo, será evaluativa (ver Hanley, 2015: 712).

17 Tal como la de Hume, la teoría de Smith es también sentimentalista, por lo que la aprobación no es un juicio sino un sentimiento placentero (ver nota 12 más arriba). En particular, la propiedad moral es aquí medida por "los sentimientos simpatéticos de un espectador imparcial y bien informado" (Smith, 1982: VII.ii.1.49).
} 
del motivo a la situación. La simpatía, de este modo, "nos da ya una primera noción de que ciertos sentimientos son apropiados para una situación y otros en cambio no lo son" (Fleischacker, 2017: 6) ${ }^{18}$.

Esta simpatía no-mecánica permite a Smith dar otro paso para mostrar cómo, a pesar de la autopreferencia innata, nuestras disposiciones emocionales están bien equipadas para restringir esa tendencia. Este paso lo da al describir la tendencia innata que todas las personas tenemos de buscar el llamado placer de la simpatía mutua, que es el placer que sentimos al comprobar que la otra persona está sintiendo lo mismo que nosotros. "Nada nos agrada tanto como comprobar que otras personas sienten las mismas emociones que laten en nuestro corazón, y nada nos disgusta tanto como la apariencia de lo contrario" (Smith, 1982: I.i.2.1), dice. Y agrega de inmediato que el amor propio no puede explicar esta tendencia, porque el placer o disgusto lo sentimos tan instantáneamente, y en situaciones tan triviales, que no es plausible que derive de una consideración respecto al propio interés ${ }^{19}$. La naturaleza - dice Smith- enseña tanto al espectador como al agente a asumir las circunstancias del otro; a ponerse en su situación y considerar qué sentiría si estuviera en sus zapatos. Asimismo, desde la perspectiva del otro pueden también mirarse a sí mismos como si fueran espectadores de su propia situación. Y "como esa pasión reflejada ... es mucho más débil que la original, abate necesariamente la violencia de lo que [ambos] sentían antes de llegar a la presencia [del otro]" (Smith, 1982: I.i.4.8). Tanto el espectador como el agente se esfuerzan en ajustar sus pasiones al punto en que el otro pueda aceptarlas para obtener así el placer de la simpatía mutua. Esta tendencia espontánea muestra que en Smith la simpatía es "un hecho natural, casi inescapable, de la psicología humana" (Debes, 2012: 113) y que es la causa eficiente que en la interacción social se vaya produciendo una "armonía en los sentimientos y afecciones" (Smith, 1982: I.i.4.2).

Así, con la exposición del proceso simpatético, Smith se aleja de Hume describiendo una situación en la que todos los espectadores y agen-

18 Esto es lo que posteriormente se desarrollará en la idea de que aprobar moralmente significa simpatizar con los sentimientos del otro cuando nos proyectamos en su perspectiva como si fuéramos un espectador imparcial. Para este tema, ver Carrasco (2011). Como se puede apreciar ya desde la misma noción de simpatía, la moral en Smith tendrá que ver con lo apropiado, con la proporcionalidad de los sentimientos a la realidad. En Hume, en cambio, la moral se relaciona con el poder de producir utilidad o agrado.

19 Igual que Hume en su obra, Smith se ocupa de rechazar explícitamente las interpretaciones egoístas de la moral (i.e. las que interpretan la aprobación moral exclusivamente en base al amor propio). Ver también Smith, 1982: VII.iii.1.4. Para los argumentos de Hume, 1998: Apéndice 2. 
tes están desde siempre comprometidos en un proceso de ajuste emocional. Este esfuerzo recíproco tiene dos grandes consecuencias. Primero, a nivel social, induce a una cierta concordia de sentimientos, "que es suficiente para alcanzar la armonía social” (Smith, 1982: I.i.4.7). Esto era todo lo que Hume requería de la moral; pero para Smith esto no basta. Él no cree que haya verdadera armonía sin verdadera virtud. Por eso, la segunda consecuencia del proceso simpatético es que, a nivel personal, los esfuerzos del agente y del espectador por ajustar sus sentimientos son el comienzo del proceso de adquisición de disposiciones virtuosas ${ }^{20}$.

\subsection{La conciencia y la virtud del self-command}

Debido al deseo innato de sentirnos aprobados por los demás, comenzamos a sentirnos ansiosos por saber cómo nos juzgan los otros, y empezamos a examinar nuestras propias pasiones y conducta ${ }^{21}$. Lo hacemos siguiendo el mismo patrón con el que juzgamos las pasiones y conducta de los demás, suponiéndonos espectadores de nosotros mismos e imaginando cómo nos juzgaríamos bajo esa luz. Nos dividimos en dos, el juez, en cuyos sentimientos respecto de mi conducta intento entrar; y el agente, cuya conducta está siendo juzgada (Smith, 1982: III.1.6). Este autodistanciamiento inducido por el deseo de sentirse aprobado por los otros y operado por la identificación simpatética es, en la teoría de Smith, el origen empírico de la conciencia moral ${ }^{22}$.

Desde nuestra propia perspectiva nuestros intereses se verán siempre como si fueran muchísimo más importantes que los intereses de los demás. Por eso debemos aprender a salir de esta perspectiva, cambiar a la posición de un tercero, a la de un espectador imparcial sin relación particular con ninguna de las partes involucradas. Desde ese punto de vista vemos que "no somos más que uno en la multitud, en ningún sentido mejor que cualquier otro en ella; y si nos prefiriéramos tan vergonzosa y ciegamente a los demás, nos volveríamos el objeto propio de resentimiento"

\footnotetext{
20 "Sobre esos dos esfuerzos distintos [el del espectador y el del agente] se fundan dos conjuntos de virtudes diferentes" (Smith, 1982: I.i.5.1). Ver también Fleischacker (2017: 3).

21 Dice Smith: "la mayor parte de la felicidad humana proviene de la conciencia de ser amado" (Smith, 1982: I.ii.5.1). En la Conclusión de la Enquiry, Hume también alude a la importancia de la opinión que los demás tienen de uno, afirmando que nuestra preocupación por esa opinión es el mejor resguardo para la virtud (Hume, 1998, 9.10). Pero en Hume este no es un elemento central de su ética, como sí lo es para Smith.

22 En consecuencia, y entendida como un subproducto de nuestra tendencia innata a la simpatía mutua y nuestros permanentes enlaces en relaciones simpatéticas, la conciencia es una completa novedad respecto de la ética sentimentalista de Hume.
} 
(Smith, 1982: III.3.4). Este espectador imparcial imaginario, o "la razón, el principio, la conciencia... el gran juez y árbitro de nuestra conducta," es quien corrige las distorsiones que produce el amor propio. El hábito y la experiencia, además, nos enseñan a cambiar de punto de vista tan fácil y rápidamente que apenas nos damos cuenta de que lo hacemos (Smith, 1982: III.3.3-4). Solo desde esta perspectiva imparcial la persona puede juzgar acerca de la propiedad de sus propios sentimientos y motivos, y corregir el autoengaño que representa la sobrevaloración de su propia perspectiva (Darwall, 1999: 153; Debes, 2012: 114).

La aparición de la figura del supuesto espectador imparcial en la TMS no solo muestra el origen del proceso con el que Smith busca corregir la autopreferencia, sino que también evidencia su fuerte compromiso con la normatividad moral -algo más bien ausente en la moral funcional de Hume. Dice Smith que los espectadores externos solo son jueces de primera instancia, pues las personas pueden apelar "a un tribunal muy superior, el de sus propias conciencias, el del supuesto... espectador imparcial" (Smith, 1982: III.2.32). La jurisdicción del hombre de fuera se funda en el deseo de alabanza; la del hombre interior, en cambio, en el deseo de ser dignos de alabanza ${ }^{23}$. La aparición del espectador imparcial, entonces, abre una nueva dimensión en esta ética. Crea una perspectiva inédita desde la que podemos discernir cuáles "deben ser los sentimientos de los otros respecto de nuestro carácter y conducta” (Smith, 1982: III.2.25) —o, lo que es lo mismo, cuáles deben ser nuestros motivos y sentimientos. Desde el momento en que surge este espectador en el pecho, nuestros sentimientos tienen algo a lo que aspirar, tienen un estándar con el que pueden ser medidos y juzgados (Fleischacker, 2017: 7): tienen una norma, una medida, específicamente, una normatividad moral ${ }^{24}$.

Tanto el deseo de alabanza como el de ser digno de ella son naturales, distintos e independientes (Smith, 1982: III.2.2) ${ }^{25}$. El segundo solo se satisface con la aprobación simpatética del espectador imparcial, lo que significa que, para la ética de Smith, el amor a la autoaprobación es, en definitiva, amor a la virtud (Smith, 1982: III.2.8). Esto es importante porque "[n]os complace pensar que nos hemos vuelto el objeto natural de aprobación [i.e. que el espectador imparcial nos aprueba] aunque nadie nos

23 El deseo de ser el objeto propio de alabanza no está presente en Hume, y como Smith bien muestra, ser solo "alabado" por los otros no garantiza que se esté siendo el objeto digno de aprobación.

$24 \quad$ Esto es muy claro en TMS (Smith, 1982: VII.ii.1.49): "Esa medida precisa y distinta [con la que se juzga la propiedad de un afecto] no puede encontrarse en ningún lugar más que en los sentimientos simpatéticos de un espectador imparcial bien informado".

25 Aunque en una mente bien formada, dice Smith, el segundo deseo es más fuerte (Smith, 1982: III.2.7). 
apruebe actualmente; y nos mortifica saber que nos hemos ganado la condena de quienes nos rodean [i.e. que el espectador imparcial nos desaprueba] aunque nadie albergue ese sentimiento en contra de nosotros" (Smith, 1982: III.2.5). La aparición del segundo tribunal, la conciencia, permite a esta ética dar a los juicios morales cierta independencia respecto de los sentimientos actuales de quienes nos rodean. La autoaprobación y la autocondena (o la aprobación y condena del espectador imparcial) no dependen de una transfusión mecánica de sentimientos à la Hume. El terror a ser digno de condena es un fuerte motivo para contrarrestar la autopreferencia.

Sin embargo, saber qué es apropiado no basta para restringir nuestras pasiones $^{26}$. En la sexta parte de la TMS, cuando Smith comienza a exponer acerca del carácter de la persona virtuosa, señala —en lo que podría interpretarse como un gesto hacia Hume- que "cuando consideramos el carácter de un individuo lo vemos naturalmente bajo dos aspectos diferentes; primero, según cómo afecta su propia felicidad; y segundo, según cómo afecta la felicidad de los demás" (Smith, 1982: VI.introd.1) ${ }^{27}$. Sin embargo, inmediatamente agrega una tercera disposición: el self-command ${ }^{28}$. Para Smith no hay virtud sin self-command, del que "todas las demás parecen derivar su mayor lustre" (Smith, 1982: VI.iii.11). De hecho, el self-command debe acompañar a todas las virtudes porque en esta teoría la virtud se entiende como la adecuada regulación de las pasiones realizada por el mismo agente (Smith, 1982: VII.ii.introd.1) ${ }^{29}$. Las virtudes requieren que seamos "dueños de nosotros mismos", que nos "adueñemos" de nuestras pasiones. Coincidentemente la primera vez que Smith utiliza esta expresión es cuando describe el proceso simpatético y el esfuerzo que el agente y el

26 Hume también se da cuenta de este rasgo propio de los seres humanos, como se manifiesta cuando señala que "Aunque estemos plenamente convencidos de que [un] objeto supera a [otro], somos incapaces de regular nuestras acciones mediante este juicio" (Hume, 2007: 3.2.7.2). La solución de Hume a este problema, como ya vimos, es cambiar las circunstancias externas. La de Smith será la adquisición y ejercicio del self-command.

$27 \quad$ Esta distinción de virtudes entre las que dan felicidad al agente y las que la dan a los demás recuerda que para Hume un rasgo virtuoso es aquel útil/agradable para el mismo agente o útil/agradable para los demás. Smith dedica una sección de la Parte VI a cada uno de estos dos tipos de virtudes, pero luego agrega una tercera sección: Del self-command.

28 Mantengo el término en inglés puesto que, como señala Montes, con este Smith alude tanto al "autocontrol" como la "autodirección;" y en español no parece haber un término que reúna ambos significados (Montes, 2004: 112, n.20).

29 Nótese la diferencia de esta definición respecto de la de Hume, para quien las virtudes son "una cualidad de la mente agradable o aprobada por todos quienes la consideran o contemplan" (Hume, 1998: 8, n.50). Claramente el concepto smithiano se acerca más a la tradición de la moral realista clásica (como él mismo lo reconoce en TMS, Smith, 1982: VII.ii.1.12). 
espectador realizan para atenuar sus pasiones al punto en que el otro pueda compartirlas (Smith, 1982: I.i.4.9).

De este modo, el deseo innato de simpatía mutua nos induce a controlar nuestros sentimientos de primer orden. Un niño pequeño no tiene self-command y no aprende a refrenar su autopreferencia hasta relacionarse con iguales que no toleran su parcialidad. "Naturalmente desea ganarse su favor y evitar su odio o desprecio ... pronto comprende que solo lo podrá lograr si modera .... todas sus pasiones, a un punto en el que sus compañeros puedan sentirse cómodos. Entra entonces a la gran escuela del selfcommand, reflexiona sobre cómo ser cada vez más dueño de sí, y empieza a ejercitar sobre sus propios sentimientos una disciplina que la práctica de la vida más prolongada rara vez resulta suficiente para conducir a la total perfección" (Smith, 1982: III.3.22). El self-command es una virtud, una disposición adquirida que se desarrolla con el ejercicio, y sin la que "las pasiones, en la mayoría de las circunstancias, se precipitarían de cabeza ... hacia su propia satisfacción" (Smith, 1982: VI.concl.2). En definitiva, el self-command, disposición que surge del proceso simpatético, es la virtud que hace posible el balance de amor propio y respeto hacia los demás, el principal desafío que enfrenta el hombre virtuoso (Hanley, 2015: 720).

Hay al menos tres diferencias esenciales entre el self-command y las convenciones que propone Hume como medios para compensar la autopreferencia. Primero, el self-command regula los impulsos egoístas desde dentro, no alterando las circunstancias externas. Segundo, el self-command no se aprueba por su utilidad ${ }^{30}$. Smith afirma que las otras virtudes son aprobadas tanto por su utilidad como por su propiedad, pero el self-command, "nos es recomendado principal y casi completamente ... por un sentido de propiedad, por concordar con los sentimientos del supuesto espectador imparcial" (Smith, 1982: VI.concl.2). Smith reconoce que podemos restringir nuestras pasiones por razones prudenciales, como en la teoría de Hume; sin embargo, en estos casos, las pasiones son "inflamadas por la represión, y a veces ... estallan de modo absurdo e inesperado con diez veces más furia y violencia" (Smith, 1982: VI.concl.4). Al contrario, cuando las restringimos por el sentido de propiedad, "las pasiones son en cierto modo moderadas y dominadas por este sentido" (Smith, 1982: VI.concl.4). Esta es la tercera diferencia del medio que estos dos filósofos encuentran para controlar el amor propio. La estrategia de Smith, a diferencia de Hume, implica la posibilidad de moderar y transformar nuestros impulsos innatos, no solo redirigirlos.

30 Esta es una importante diferencia entre el self-command y la virtud de la "fuerza de espíritu" (strength of mind) de Hume (2007: 2.3.3.10). 


\subsection{Autotransformación}

La teoría moral de Smith "está guiada por la idea de que siempre queremos tener sentimientos que los otros puedan compartir" (Fleischacker, 2012: 300). Esta motivación psicológica es la que nos lleva a hacer el esfuerzo de ajustar nuestros sentimientos a los que creemos que un espectador imparcial aprobaría, y es la puerta que abre Smith para pasar del ámbito de la mera psicología a la normatividad moral. Esto es posible por la que parece ser una diferencia crucial entre estas dos teorías sentimentalistas: los sentimientos, para Smith, no son reacciones automáticas impermeables a la razón. En la TMS los sentimientos son maleables, responden a la crítica y pueden ser modulados por el mismo agente (Fleischacker, 2017: 7). De hecho, el hombre sabio y virtuoso está constantemente ejercitando su self-command en vistas a modelar, "no solo su conducta externa sino, en la medida de lo posible, sus sentimientos internos, de acuerdo con los [del espectador imparcial]. No solo aparenta tener los sentimientos del espectador imparcial, sino que realmente los adopta. Casi se identifica y se convierte en el espectador imparcial" (Smith, 1982: III.3.25). En contraste con Hume, quien dice que ni el estudio, el consejo y la resolución son medios efectivos para curar el amor propio, Smith cree que la virtud no es algo que simplemente "le pase" a la persona (o "pase en" la persona), sino una disposición que ella misma debe desarrollar activamente ${ }^{31}$.

Asimismo, la mera apariencia de virtud -o una conducta externa bien adaptada - no basta en Smith, ni siquiera para alcanzar la armonía social. Solo el amor a lo que es digno de alabanza hace al hombre realmente apto para la sociedad (Smith, 1982: III.2.7; también VI.3.3) ${ }^{32}$. La restricción de las pasiones antisociales por razones prudenciales es contraproducente. Solo cuando se restringen por simpatía con los sentimientos más templados del espectador, el agente logra ver la situación bajo otra luz y sus pasiones cambian ajustándose a ese estándar. Esta es la única garantía posible para la vida social armoniosa. La teoría de los sentimientos morales de Smith es una ética de la autotransformación, de sentimientos moralizados, en la que el amor propio se supera por "el sentido de la propiedad y de la

\footnotetext{
31 En la teoría de Smith el hombre virtuoso se esfuerza en asimilar su propio carácter a ese "arquetipo de perfección"; observando y estudiando la idea de "propiedad exacta"; ejercitando el control sobre sus sentimientos pasivos y habituando sus pasiones (Smith, 1982: VI.iii.25).

32 Contrástese con Hume: "[A]unque no siempre intervenga el corazón en estas nociones generales, ni regule sus sentimientos de amor u odio por ellas, son, con todo, suficientes para permitirnos hablar con sentido, y sirven a todos nuestros propósitos en la vida común, sea en el púlpito, en el teatro o en las escuelas" (Hume, 2007: 3.3.3.2).
} 
justicia [que] corrigen la desigualdad de nuestros sentimientos" (Smith, 1982: III.3.3).

\section{CONCLUSIÓN}

Hume y Smith piensan que así como la vida social nos brinda la asistencia mutua que las personas necesitamos para subsistir; por nuestra tendencia innata a la autopreferencia, esta misma vida social nos expone también al daño mutuo (Smith, 1982: II.ii.3.1). Por eso el desafío de la moral, según estos filósofos escoceses, es encontrar los medios para restringir el amor propio. Sus soluciones son muy distintas; en parte por lo que cada cual piensa que es la función de la moral, y en parte por su visión de la naturaleza del "material" con el que realiza esa función. Los sentimientos, para Hume, son fuerzas ciegas que se pueden manipular desde fuera cambiando las circunstancias ante las que reaccionan. Así, una convención social que re-localice los objetos de las pasiones antisociales puede redirigirlas hacia fines socialmente útiles. Las convenciones son como un sistema de tuberías que, sacando provecho de la fuerza de gravedad, canaliza y reconduce el agua de manera de que, en vez de principio de destrucción, el agua sea un principio de vida.

En contraste con este dispositivo mecánico para controlar la autopreferencia, Smith piensa que el proceso simpatético modela nuestros sentimientos desde su origen ${ }^{33}$. Es decir, antes que una corrección externa y sobreagregada a las emociones - como las tuberías que canalizan las pasiones sin cambiarlas- la ética de Smith podría interpretarse como el esqueleto que da forma y sostiene al cuerpo: El sentido de propiedad —el sentido de lo apropiado para cada situación particular-informa nuestras pasiones de primer orden transformándolas en sentimientos morales. No se necesitan represas y diques artificiales porque la moral es inmanente a nuestras disposiciones: las corrige desde dentro.

Por otro lado, el proceso simpatético en Smith está también en la base de todas nuestras relaciones sociales, permitiendo dar una explicación unificada de la interacción humana — sin necesidad de dividir áreas según grados de cercanía, como hace Hume. Mostrando que nuestra tendencia a la simpatía mutua, entendida como identificación y esfuerzo recíproco de ajustar los sentimientos, es un hecho inescapable de nuestra psicología; y

\footnotetext{
33 Sería interesante investigar hasta qué punto sería posible analizar algunas de las instituciones sociales que describe Smith en la Riqueza de las Naciones, como por ejemplo la división del trabajo (Smith, 1981: I.1), la educación de las mujeres (Smith, 1981: V.i.f.47), etc., con un esquema similar a las convenciones humeanas. Sin embargo, el modelo no se aplicaría al ámbito de la moral.
} 
mostrando que "el impulso al juicio moral está ya contenido en los movimientos naturales de nuestras emociones" (Fleischacker, 2012: 294), Smith puede dar cuenta de cómo las personas entran en una comunidad moral. A diferencia de las convenciones que manipulan las pasiones para integrarlas en un sistema cooperativo, la simpatía mutua transforma y moraliza nuestras pasiones. Gracias a esa tendencia inescapable se engendra la conciencia moral, el "tribunal superior" que no cabe en la ética de Hume, pero que en Smith se convierte en la fuente de la normatividad moral. Así, aunque los dos sentimentalistas escoceses encuentran el modo de integrar las tendencias egoístas en la acción propiamente virtuosa, la solución de Hume se conforma con evitar su potencia destructiva, mientras que la ética de Smith aspira a transformarlas.

\section{REFERENCIAS}

-Carrasco, M. A. (2011). From Psychology to Moral Normativity. The Adam Smith Review, 6, 9-29.

-Cohon, R. (2008). Hume's Morality: Feeling and Fabrication. New York: Oxford University Press.

-Darwall, S. (1998). Empathy, Sympathy, Care. Philosophical Studies, 89, 261-282.

-Darwall, S. (1999). Sympathetic Liberalism: Recent Work on Adam Smith. Philosophy \& Public Affairs, 28(2), 139-164.

-Debes, R. (2007). Has anything changed? Hume's Theory of Association and Sympathy after the Treatise. British Journal for the History of Philosophy, 15(2), 313-338.

-Debes, R. (2012). Adam Smith on Dignity and Equality. British Journal for the History of Philosophy, 20(1), 109-140.

-Fleischacker, S. (2012). Sympathy in Hume and Smith: A Contrast, Critique, and Reconstruction. En C. Fricke \& D. Follestal (eds.): Intersubjectivity and Objectivity in Adam Smith and Edmund Husserl (pp. 273-311). Heusenstamm: Ontos Verlag.

-Fleischacker, S. (2017). Adam Smith's Moral and Political Philosophy. Recuperado de E. Zalta (ed.), The Stanford Encyclopedia of Philosophy, URL = $<$ https://plato.stanford.edu/archives/spr2017/entries/smith-moral-politi$\mathrm{cal} />$

-Hanley, R. (2015). Hume and Smith on Moral Philosophy, en Russell, P. (Ed.), The Oxford Handbook of Hume (pp. 708-728). Nueva York: Oxford University Press.

-Hume, D. (1998). An Enquiry concerning the Principles of Morals (T. Beauchamp, ed.). Oxford: Oxford University Press.

-Hume, D. (2007). A Treatise of Human Nature (D. F. Norton y M. J. Norton, eds.). Oxford: Oxford University Press.

-Montes, L. (2004). Adam Smith in Context. Nueva York: Palgrave Macmillan. 
-Sayre-McCord, G. (2014). Hume and Smith on Sympathy, Approbation and Moral Judgment. Social Philosophy and Policy, 30(1-2), 208-236.

-Smith, A. (1981). An Inquiry into the Nature and Causes of the Wealth of Nations (R. H. Campbell y A. S. Skinner, eds.). Indianapolis: Liberty Fund.

-Smith, A. (1982). The Theory of Moral Sentiments (D. D. Raphael y A. L. Macfie, eds.). Indianapolis: Liberty Fund.

Sumario: Introducción. 1. David Hume; 1.1. Círculos de cercanía y tipos de motivación; 1.2. El automatismo de las pasiones; 2. Adam Smith; 2.1. La conciencia y la virtud del self-command; 2.2. Autotransformación; Conclusión; Referencias. 